\title{
ANALISIS PENGARUH MOTIVASI, ORGANISASI DAN SOFT SKILL TERHADAP KINERJA MAHASISWA FAKULTAS TEKNIK UNIKA ATMAJAYA ANGKATAN 2012
}

\author{
Andre Sugioko ${ }^{1}$, Trifenaus Prabu Hidayat ${ }^{2}$, Maria Goretti Yostiana Putri ${ }^{3}$ \\ Jurusan Teknik, Industri Fakultas Teknik, Universitas Katolik Indonesia Atma Jaya Jakarta ${ }^{1,2,3)}$ \\ Jl. Jendral Sudirman 51, Jakarta, 12930 \\ E-mail : andresugioko@yahoo.com ${ }^{1}$,trifenausprabuhidayat@gmail.com², \\ adrianfortunasetiawan@yahoo.com ${ }^{3}$
}

\begin{abstract}
College Students as the input of a university, have different attitudes and learning outcomes from one another. Education as one way to achieve the goal, can be assessed and seen through the performance. The performance is in question is the achievement of a student focusing on college events. The performance of the students in college year not rated academically, but also nonacademic. According to some studies, the performance can be assessed with motivation, organization and soft skills. This study aims to measure the influence of motivation, organization, and soft skills of the students' performance. The focus of this research is a student in the fourthyear college or the student class of 2012, which is considered to have a lot of experience that can be measured in this study. Processing data using Structural Equation Modeling with Amos. The results of this study are, Motivation has an influence on student performance, while the Organization and Soft skills have no effect on student performance.
\end{abstract}

Keywords : Organization, Soft skills, Performance, College Student, SEM.

\section{PENDAHULUAN}

Pendidikan dan pengajaran adalah suatu proses yang sadar tujuan. Tujuan dapat diartikan sebagai suatu usaha untuk memberikan rumusan hasil yang diharapkan peserta didik setelah melaksanakan pengalaman belajar. Tercapai tidaknya tujuan pengajaran salah satunya adalah terlihat dari kinerja yang dihasilkan oleh peserta didik. Dengan kinerja yang baik, peserta didik mempunyai indikasi memiliki pengetahuan akademik dan non akademik yang baik.

Salah satu output yang menjadi harapan masa depan sebagai generasi bangsa adalah mahasiswa. Mahasiswa sebagai input suatu Perguruan Tinggi mempunyai sikap dan penilaian terhadap proses belajar mengajar yang berbeda. Perguruan Tinggi juga berupaya memberikan stimulan untuk mengajarkan, menumbuhkan, dan mengembangkan potensi yang dimiliki oleh setiap mahasiswa agar dapat mewujudkan prestasi atau kinerja yang optimal. Kinerja mahasiswa dalam perkuliahan dapat diukur secara akademik dan non akademik.

Kinerja adalah hasil yang diberikan oleh seseorang dalam menjalankan tugas dan tanggung jawab yang dibebankan kepadanya. Setiap yang terlihat mengenai bagaimana individu tersebut berperilaku, akan menunjukkan perannya dalam suatu organisasi. Untuk meningkatkan kinerja dapat dilakukan dengan meningkatkan motivasi belajar bagi peserta didik yang terstruktur dan terkonstruk dengan baik. Secara sederhana definisi motivasi dapat diartikan sebagai dorongan. Munandar (2001) juga menjelaskan bahwa motivasi adalah suatu proses dimana kebutuhankebutuhan mendorong seseorang untuk melakukan kegiatan yang mengarah ketercapaian tujuan tertentu.

Di zaman yang terus berkembangan dalam banyak hal menuntut adanya mahasiswa yang berprestasi tidak hanya dalam prestasi akademik tapi juga prestasi non akademik, diantaranya, kepemimpinan, manajemen waktu, pembangunan karakter, 
pergaulan efektif dan pengalamanpengalaman yang tidak hanya didapat dalam proses belajar diperkuliahan namun dibutuhkan dalam kehidupan masyarakat. Tuntutan pekerjaan saat ini banyak lapangan pekerjaan yang membutuhkan calon pelamarnya memiliki serangkaian kemampuan yang dapat diandalkan, baik kemampuan hard skill maupun soft skill. Mahasiswa dituntut untuk memiliki dua kemampuan tersebut. Dengan dua kemampuan ini diharapkan mahasiswa dapat menjadi solusi atas masalah dimasa mendatang. Dari penelusuran atau kajian formal yang pernah dilakukan, ditemukan yang membawa atau mempertahankan orang di dalam sebuah kesuksesan $80 \%$ ditentukan oleh soft skills yang dimilikinya dan $20 \%$ hard skills.

Organisasi kemahasiswaan merupakan wahana dan sarana pengembangan diri mahasiswa ke arah perluasan wawasan peningkatan ilmu dan pengetahuan, serta integritas kepribadian mahasiswa.Untuk menampung dan menyalurkan segenap pembawaan individu yang berbeda maka kehadiran organisasi menjadi vital adanya. Ada anggapan bahwa mengikuti organisasi di kampus dapat menghambat prestasi bahkan membuat mahasiswa semakin lama dalam menyelesaikan studinya. Tentunya tidak sedikit mahasiswa yang mengikuti organisasi dikampus meraih prestasi akademik yang lebih baik daripada prestasi akademik mahasiswa yang tidak ikut organisasi. Muttaqiyathun (2012) mengungkapkan, dalam kehidupan organisasi pun mesti mengikut sertakan emosi didalamnya yang akan membawa kesuksesan nantinya, agar termotivasi untuk terus maju.
Disinilah salah satu peran organisasi di kampus dalam mendukung anggotanya untuk meraih prestasi akademik yang membanggakan.

Universitas Katolik Atmajaya memiliki salah satu Fakultas yang patut diperhitungkan dalam dunia kerja, yaitu Fakultas Teknik. Dalam kehidupan teknik, mata kuliah yang diajarkan tidak hanya yang berkaitan dengan teknik saja, namun meliputi seluruh lingkup kehidupan. Selain itu, kehidupan di teknik lebih banyak melakukan sesuatu secara bersama-sama atau dalam suatu organisasi, yang tentunya dalam berorganisasi itu sendiri mahasiswa harus bisa menyesuaikan diri satu sama lain. Untuk mencapai suatu kinerja yang baik dan maksimal, tentu setiap mahasiswa perlu memiliki soft skill, motivasi serta organisasi yang baik. Ketiga faktor tersebut tentu akan mempengaruhi hasil akhir yang ingin dicapai oleh mahasiswa baik secara individual maupun kelompok.

Beberapa penelitian yang dibaca belum ada penelitian yang mencari hubungan antara soft skill, motivasi serta organisasi terhadap kinerja mahasiswa. Dimana penelitian yang pernah ada beberapa diantaranya pengaruh Kecerdasan Intelektual, Kecerdasan Emosional, Kecerdassan Spiritual Terhadap Kinerja baik dalam universitas, kinerja karyawan, kinerja wiraswasta. Sedangkan penelitian lainnya berfokus menganalisa pengaruh motivasi terhadap kinerja, dan pengaruh keaktifan organisasi terhadap kinerja. Berdasarkan latar belakang dan beberapa penelitian yang telah ada, maka Penelitian ini akan membahas Pengaruh Motivasi, Organisasi dan Soft skill terhadap Kinerja Mahasiswa. 


\section{METODOLOGI PENELITIAN}

Berikut adalah penjelasan dari metodologi penelitian dan tahap - tahap pengumpulan data : Uraian proses penelitian secara lengkap dapat dilihat pada gambar 1 .

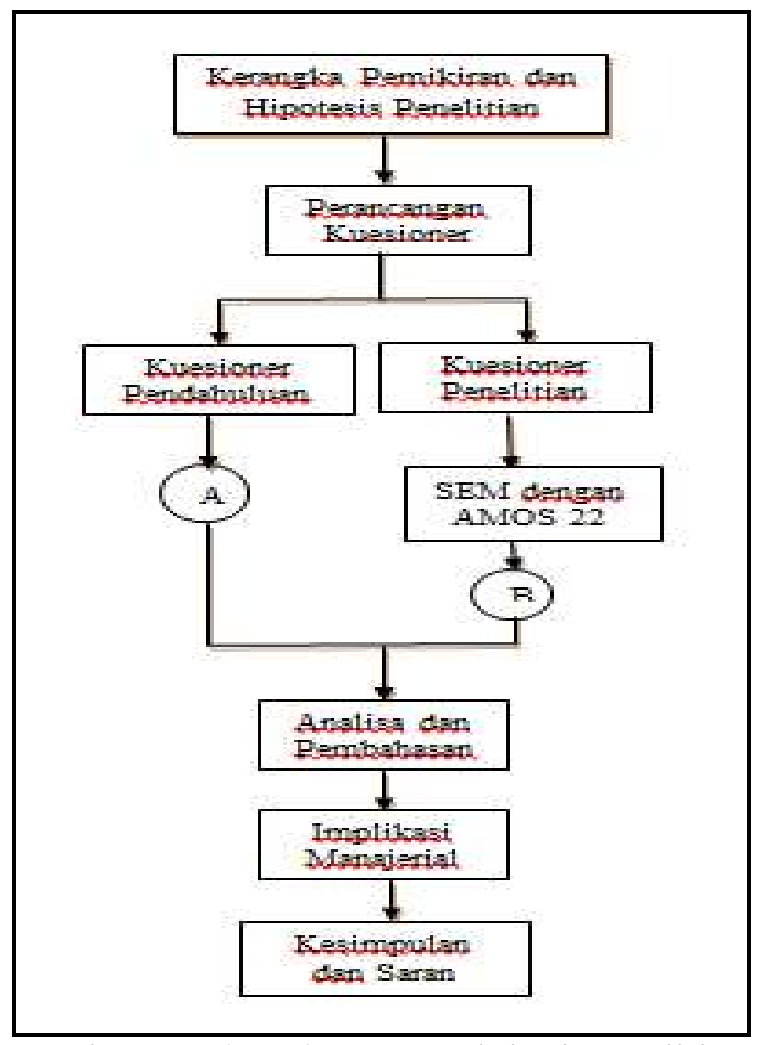

Gambar 1. Flowchart Metodologi Penelitian.

\subsection{Kerangkan Pemikiran dan Hipotesis Penelitian}

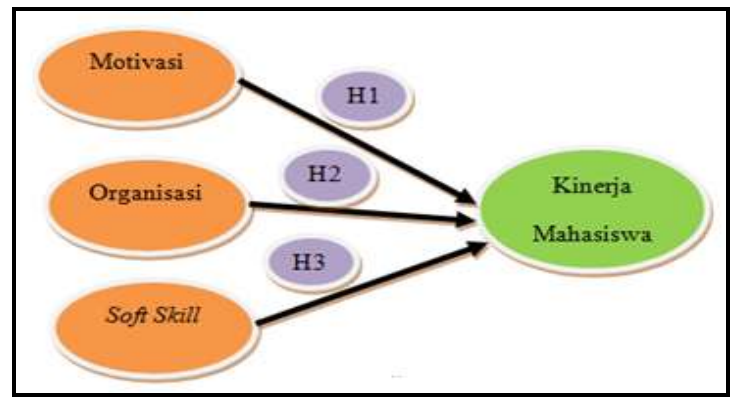

Gambar 2. Kerangka Pemikiran.

\subsubsection{H1 : Motivasi Berpengaruh terhadap Kinerja Mahasiswa}

Djalali (2008) menjelaskan bahwa motivasi merupakan salah satu aspek dari kepribadian seseorang, yang merupakan faktor vital yang sangat mempengaruhi efektivitas proses belajar mengajar serta dalam rangka pengembangan institusi pendidikan. Hal ini memperkuat pernyataan bahwa kepribadian subyek juga dapat mempengaruhi motivasinya dalam belajar. Menurut Bimo dan Nilawati, motivasi belajar merupakan dorongan untuk memenuhi kebutuhan mahasiswa dalam mencapai prestasi akademik.

\subsubsection{H2 : Organisasi Berpengaruh terhadap Kinerja Mahasiswa}

Menurut Mangkunegara (2002), faktor organisasi dapat dikategorikan sebagai hasil dari dukungan organisasi atau faktor yang berasal dari luar diri seseorang. Ketika karyawan memahami nilai - nilai yang ada dalam organisasinya, maka akan mempengaruhi bagaimana kinerjanya. Pratiwi (2012) dalam penelitiannya menjelaskan bahwa budaya organisasi mempunyai pengaruh yang signifikan terhadap kinerja karyawan. Namun, dalam penelitian ini obyek penelitian adalah mahasiswa.

\subsubsection{H3 :Soft skill Berpengaruh terhadap Kinerja Mahasiswa}

Kecerdasan intelektual hanya menyumbang 20 persen dalam peningkatan kinerja, sedangkan 80 persen dipengaruhi oleh bentuk - bentuk kecerdasan lain seperti kecerdasan emosional. Seseorang yang memiliki kecerdasan emosional mampu untuk mengatur perasaan nya dengan baik, memotivasi diri sendiri, berempati ketika menghadapi gejolak emosi diri maupun dari orang lain. Bulan, Sandiyah (2011) dan Trisnawati (2012) menyatakan terdapat hubungan positif dan signifikan antara kecerdasan emosional dengan kinerja.

\subsection{Pengumpulan dan Pengolahan Data}

Pengumpulan data dilakukan melalui penyebaran kuesioner kepada semua mahasiswa aktif Fakultas Teknik Unika Atmajaya Angkatan 2012. Penyebaran kuesioner dilakukan dalam 2 tahap, tahap pertama merupakan kuesioner pendahuluan dan tahap kedua adalah kuesioner penelitian dan pengolahan data dilakukan dengan program Amos versi 22. 
Pengumpulan data pertama menggunakan kuesioner pendahuluan dengan responden sebanyak 30 orang yang disebarkan masing-masing kepada 10 mahasiswa aktif di setiap Prodi FT UAJ Angkatan 2012 secara acak. Jumlah tersebut dianggap memenuhi syarat suatu data dapat diolah dan data dapat diasumsikan mendekati distribusi normal. Berdasarkan teorema limit sentral, rataan sampel umumnya baik apabila $\mathrm{n} \geq 30$.

Pada tahap ini tidak menutup kemungkinan apabila responden ingin memberikan saran mengenai tata bahasa atau pernyataan yang kurang tepat atau perlu ditambahkan, yang kemudian akan dilakukan perbaikan agar lebih baik. Pengumpulan data ini dilakukan secara online dengan menggunakan aplikasi "Google Form". Pengolahan data pada kuesioner pendahuluan dilakukan untuk pengecekan alat ukur berupa kuesioner sebelum kemudian dilakukan penyebaran kuesioner utama. Pengujian dilakukan dengan uji validitas dan uji reliabilitas.

Apabila kuesioner pendahuluan sudah dinyatakan valid dan realiabel maka kemudian dapat digunakan untuk mengumpulkan data terhadap kuesioner penelitian.

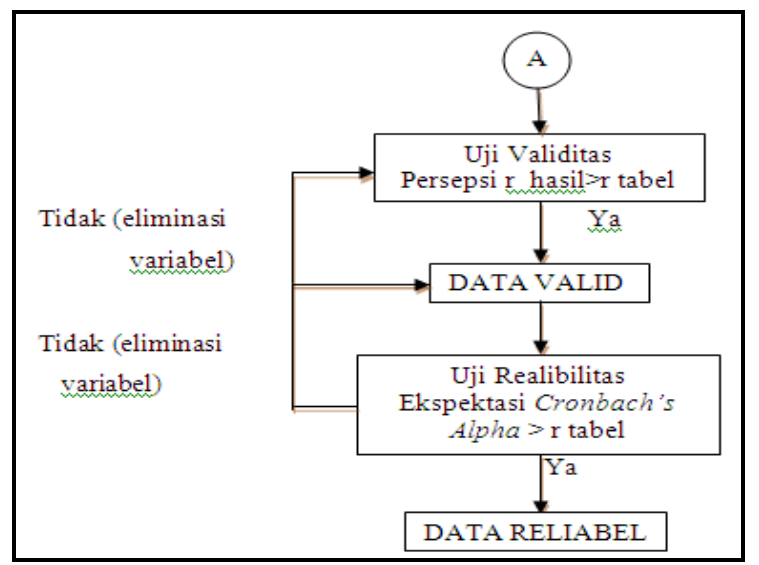

Gambar 3. Pengujian Kuesioner

Pendahuluan.

Pengujian validitas dilakukan dengan menggunakan rumus korelasi product moment pearson yang diolah dengan bantuan Software SPSS. Dengan jumlah responden 30 orang, serta tingkat ketelitian yang digunakan $\alpha 5 \%$ maka diperoleh $\mathrm{r}$ tabel $=$ 0.361. Dari perhitungan tersebut menghasilkan butir-butir yang valid dan yang tidak valid, dengan membandingkan $r$ hitung dengan $r$ tabel. Apabila $r$ hitung lebih besar dari $r$ tabel $\left(r_{h}>r_{t}\right)$ maka butir instrumen tersebut valid, tetapi sebaliknya bila $r$ hitung lebih kecil dari $r$ tabel $\left(r_{h}<r_{t}\right)$ maka instrumen tersebut tidak valid dan tidak dipergunakan dalam penelitian.

Hasil uji validitas dari 37 item pernyataan, dinyatakan valid untuk 33 item dan 4 item lainnya yaitu item 3 , item 9 , item 29 dan item 33 dinyatakan tidak valid karena hasil $\mathrm{r}$ hitung $<\mathrm{r}$ tabel. Item pernyataan yang tidak valid kemudian dibuang dan akan dilakukan pengujian validitas kembali dengan 33 item yang dinyatakan valid.

Metode yang digunakan untuk pengujian reliabilitas dalam penelitian ini ditentukan berdasarkan nilai Alpha Cronbach yang didapat dengan bantuan Software SPSS. Hubungan yang reliable jika memberikan nilai Alpha Cronbach $>0,70$. Dari hasil perhitungan dilihat nilai perhitungan Cronbavh's Alpha sebesar 0.928 dan nilai tersebut $>0.70$, maka hal ini menunjukkan bahwa pernyataan pernyataan yang diajukan dalam kuesioner sudah reliable.

Setelah kuesioner pendahuluan sudah dinyatakan valid dan reliable serta sudah diperbaiki, maka dapat dibuat kuesioner penelitian yang akan digunakan sebagai alat ukur utama. Pengumpulan data pada kuesioner penelitian dilakukan terhadap mahasiswa aktif FT UAJ Angkatan 2012. Pada penelitian ini menggunakan teknik sampling sensus, dimana respondennya sejumlah populasi dari mahasiswa aktif FT UAJ Angkatan 2012 yaitu sebanyak 193 orang. Yang terdiri dari 112 orang dari Fakultas Industri, 35 orang dari Fakultas Elektro dan 46 orang dari Fakultas Mesin. Pengumpulan data dilakukan melalui kuesioner online dengan menggunakan aplikasi "Google Form". Pengolahan data menggunakan SEM dengan bantuan software amos versi 22. yang memiliki 7 langkah seperti gambar 4 . 


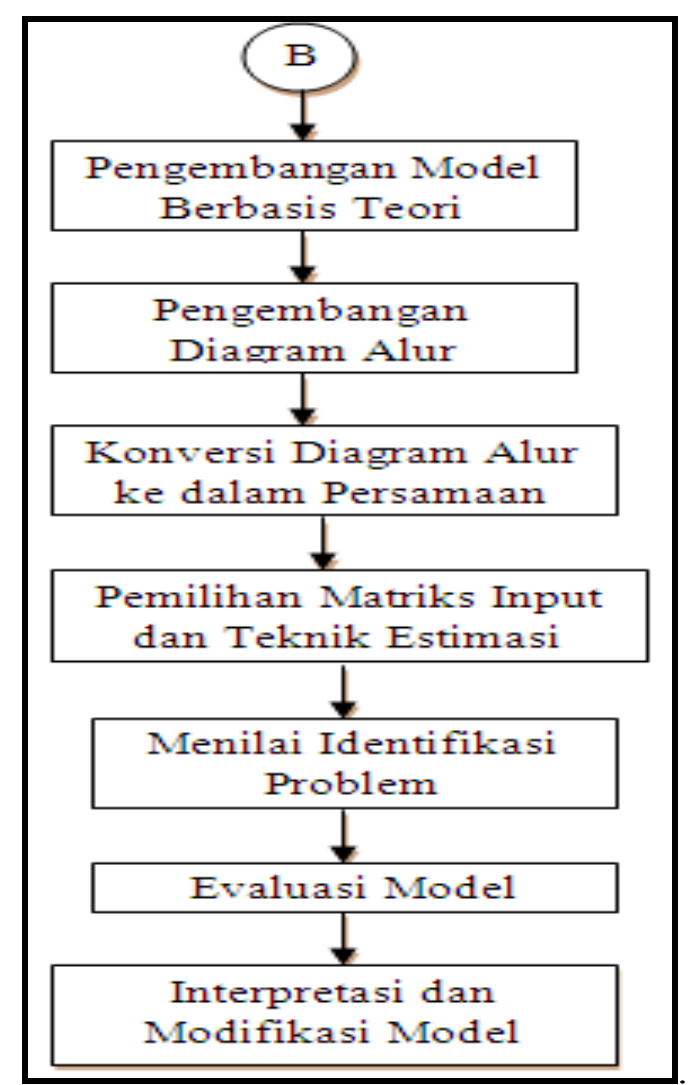

Gambar 4.Tahap Pengujian dengan AMOS.

Pada tahap awal dibuat hipotesa yang didapatkan berdasarkan kerangka pemikiran yang telah dibuat sebelumnya. Maka, terdapat tiga hipotesis pada penelitian ini.

- $\mathrm{H}_{1}$ : Motivasi Berpengaruh terhadap Kinerja Mahasiswa.

- $\mathrm{H}_{2}$ : Organisasi Berpengaruh terhadap Kinerja Mahasiswa.

- $\mathrm{H}_{3}$ : Soft skill Berpengaruh terhadap Kinerja Mahasiswa.

Berdasasarkan hipotesa dari model teoritis yang telah dibangun pada langkah awalakan digambarkan sebuah path diagram yang akan mempermudah peneliti melihat hubungan - hubungan kausalitas yang akan diuji.

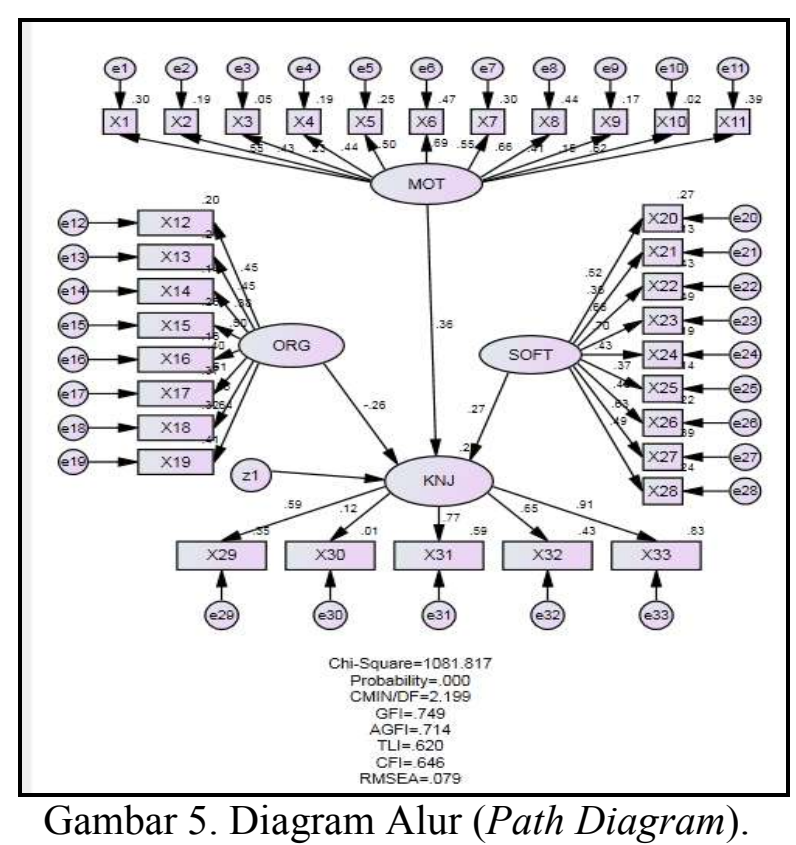

Gambar diagram alur kemudian akan dikonversikan kedalam persamaan, yaitu persamaan struktural untuk menjelaskan model secara keseluruhan dan persamaan model stuktural untuk menjelaskan masing masing konstuk.

1. Persamaan Struktural

$\mathrm{BN}]=\beta 1 \mathrm{MOT}+\beta 2 \mathrm{ORG}+\beta 3 \mathrm{SOPT}+z 1$

\section{Persamaan Model Pengukuran}

Konstruk Eksogen Motivasi

$\mathrm{x}_{\mathrm{n}}=\lambda_{\mathrm{n}} \mathrm{MOT}+\mathrm{e}_{\mathrm{n}} \mathrm{n}=1,2,3, \ldots, 11$

Konstruk Eksogen Organisasi

$\mathrm{x}_{\mathrm{n}}=\lambda_{\mathrm{n}} \mathrm{ORG}+\mathrm{e}_{\mathrm{n}} \mathrm{n}=12,13,14, \ldots, 19$

Konstruk Eksogen Soft skill

$\mathrm{x}_{\mathrm{n}}=\lambda_{\mathrm{n}} \mathrm{SOFT}+\mathrm{e}_{\mathrm{n}} \mathrm{n}=20,21,22, \ldots, 28$.

Konstruk Endogen Kinerja Mahasiswa

$\mathrm{x}_{\mathrm{n}}=\lambda_{\mathrm{n}} \mathrm{KNJ}+\mathrm{e}_{\mathrm{n}} \mathrm{n}=29,30,31, \ldots, 33$. 
Keterangan :

KNJ = kinerja mahasiswa.

MOT = motivasi.

ORG = organisasi.

SOFT $=$ soft skill.

$\mathrm{z} 1=$ error dari variabel Kinerja Mahasiswa

$\beta 1=$ parameter hubungan dari variabel motivasi ke variabel Kinerja Mahasiswa.

$\beta 2=$ parameter hubungan dari variabel organisasi ke variabel Kinerja Mahasiswa.

$\beta 3=$ parameter hubungan dari variabel soft skill ke variabel Kinerja Mahasiswa.

$\mathrm{e}_{\mathrm{n}} \quad=$ error dari indikator ke-n.

$\lambda_{\mathrm{n}}=$ parameter hubungan antara variabel laten terhadap indikator ken.

Pada tahap ini akan menggunakan teknik estimasi Maximum Likelihood (ML) yang dilakukan dengan 2 proses yaitu model pengukuran dan model struktural. Setelah dilakukan pengujian dengan teknik CFA (confirmatory factor analysis) dan setiap variabel sudah dinyatakan fit, maka model fit dari masing - masing variabel tersebut digabungkan menjadi selanjutnya model full structural. Model full structural tersebut akan di uji berdasarkan kriteria goodness of fit yang ditentukan. Full structural dari model penelitian dapat dilihat pada gambar 6.

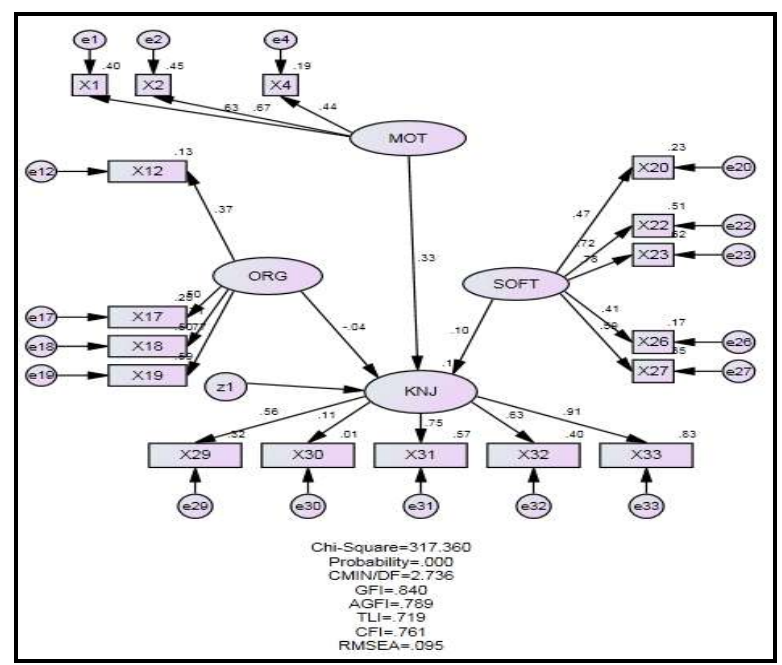

Gambar 6. Model Fit Structural Equation.
Model di atas belum fit karena nilai loading factor berada dibawah 0,5 dan belum memenuhi kriteria goodness of fit Indices. Hal ini dilihat dari nilai cmindf sebesar 2,736 yang melebihi kriteria fit yaitu dimana harus lebih kecil dari 2, nilai RMSEA sebesar 0,95 yang belum memenuhi kriteria fit yaitu antara $<0,08$, nilai GFI dan AGFI yang belum mencapai 0,9 serta nilai TLI dan CFI yang belum mendekati 0,95. Maka model ini perlu dilakukan modifikasi. Perlu dipastikan kembali apakah model tersebut dapat dilanjutkan penilaiannya dengan melihat nilai df seperti pada gambar 7 .

Jumlah momen diperoleh sebesar 153 dari model yang diolah. Jumlah parameter yang akan diestimasi adalah jumlah seluruh anak panah yang ada model. Nilai degress of freedom yang dihasilkan tidak boleh negatif, apabila nilai df negatif (under indentified) maka model tersebut tidak dapat diselesaikan sehingga estimasi dan penilaian model tidak perlu dilakukan. Pada model ini, nilai df yang dihasilkan sebesar 116 yang berarti positif (over indentified), maka estimasi dan penilaian model bisa dilakukan. Tahap berikutnya adalah melakukan evaluasi normalitas, outlier dan Kriteria GOF. Data data penelitian yang sudah didapatkan dari responden diolah untuk diuji dari sisi normalitas dan linearitas dengan AMOS 22.

Notes for Model (Default model)
Computation of degrees of freedom (Default model)
Number of distinct sample moments: 153
Number of distinct parameters to be estimated: $\quad 37$
Degrees of freedom (153 - 37): 116
Result (Default model)
Minimum was achieved
$\begin{aligned} & \text { Chi-square }=317.360 \\ & \text { Degrees of freedom }=116 \\ & \text { Probability level }=.000\end{aligned}$

Gambar 7. Degree of Freedom. 
Tabel 1. Uji Normalitas

\begin{tabular}{c|c|c|c|c|c|c}
\hline Variable & Min & Max & Skew & c.r & Kurtosis & c.r \\
\hline X29 & 1 & 4 & $-0,297$ & $-1,687$ & $-0,057$ & $-0,163$ \\
X30 & 1 & 4 & $-0,508$ & $-2,884$ & 0,692 & 1,962 \\
X31 & 1 & 4 & $-1,126$ & $-6,386$ & 0,095 & 0,27 \\
X32 & 1 & 4 & $-1,948$ & $-11,047$ & 3,076 & 8,724 \\
X33 & 1 & 4 & $-1,05$ & $-5,958$ & $-0,285$ & $-0,809$ \\
X27 & 2 & 4 & 0,116 & 0,66 & $-1,442$ & $-4,09$ \\
X26 & 2 & 4 & $-0,259$ & $-1,471$ & $-1,013$ & $-2,872$ \\
X23 & 1 & 4 & $-0,796$ & $-4,515$ & 1,148 & 3,257 \\
X22 & 2 & 4 & $-0,241$ & $-1,368$ & $-1,261$ & $-3,576$ \\
X20 & 2 & 4 & $-0,358$ & $-2,029$ & $-0,971$ & $-2,754$ \\
X12 & 2 & 4 & $-0,405$ & $-2,296$ & $-0,867$ & $-2,459$ \\
X17 & 1 & 4 & $-0,443$ & $-2,512$ & 0,308 & 0,873 \\
X18 & 1 & 4 & $-0,415$ & $-2,353$ & 0,244 & 0,692 \\
X19 & 1 & 4 & $-0,265$ & $-1,502$ & 0,36 & 1,022 \\
X4 & 1 & 4 & $-0,229$ & $-1,296$ & 0,044 & 0,124 \\
X2 & 1 & 4 & $-0,085$ & $-0,484$ & 1,124 & 3,189 \\
X1 & 1 & 4 & $-0,062$ & $-0,354$ & $-0,254$ & $-0,72$ \\
\hline Multivariate & & & & & $\mathbf{5 0 , 9 6 8}$ & $\mathbf{1 3 , 9 2 9}$ \\
\hline
\end{tabular}

Tabel 2. Revisi Uji Nornalitas

\begin{tabular}{c|c|c|c|c|c|c}
\hline Variable & Min & Max & Skew & c.r & Kurtosis & c.r \\
\hline X29 & 1 & 4 & $-0,285$ & $-1,603$ & $-0,017$ & $-0,047$ \\
X30 & 1 & 4 & $-0,532$ & $-2,993$ & 0,845 & 2,377 \\
X31 & 1 & 4 & $-1,123$ & $-6,319$ & 0,11 & 0,31 \\
X32 & 1 & 4 & $-1,964$ & $-11,049$ & 3,221 & 9,062 \\
X33 & 1 & 4 & $-1,079$ & $-6,073$ & $-0,205$ & $-0,576$ \\
X27 & 2 & 4 & 0,129 & 0,725 & $-1,43$ & $-4,023$ \\
X26 & 2 & 4 & $-0,216$ & $-1,215$ & $-1,126$ & $-3,168$ \\
X23 & 1 & 4 & $-0,793$ & $-4,461$ & 1,155 & 3,249 \\
X22 & 2 & 4 & $-0,255$ & $-1,433$ & $-1,248$ & $-3,513$ \\
X20 & 2 & 4 & $-0,352$ & $-1,978$ & $-0,968$ & $-2,722$ \\
X12 & 2 & 4 & $-0,372$ & $-2,092$ & $-0,956$ & $-2,69$ \\
X17 & 1 & 4 & $-0,304$ & $-1,712$ & $-0,008$ & $-0,022$ \\
X18 & 2 & 4 & $-0,11$ & $-0,617$ & $-0,91$ & $-2,561$ \\
X19 & 2 & 4 & 0,034 & 0,191 & $-0,626$ & $-1,76$ \\
X4 & 1 & 4 & $-0,235$ & $-1,322$ & 1,114 & 0,321 \\
X2 & 2 & 4 & $-0,266$ & 1,495 & 0,311 & 0,874 \\
X1 & 1 & 4 & $-0,067$ & $-0,379$ & $-0,22$ & $-0,618$ \\
\hline Multivariate & & & & & $\mathbf{3 6 , 0 7 9}$ & $\mathbf{9 , 7 8 3}$ \\
\hline
\end{tabular}

Pada uji normalitas, nilai kurtosis harus bernilai lebih kecil dari 10. Sedangkan menurut Ghozali, nilai skewness harus sebesar $\pm 1,96$ pada tingkat signifikansi 0,05 .
Berdasarkan hasil pada Tabel 1 . disimpulkan bahwa data tidak normal karena memiliki nilai kurtosis lebih dari 10 dan masih terdapat nilai jauh dari rentang $\pm 1,96$ dan berikutnya akan dilihat pada evaluasi outiers multivariate. 
Tabel 3. Evaluasi Kriteria Goodness of Fit

\begin{tabular}{c|c|c|c}
\hline Goodness of fit Indicies & Cut Off Model & Hasil Pengujian & Keterangan \\
\hline cmin/df & $\leq 2[53]$ & 2,695 & Tidak Fit \\
RMSEA & $\leq 0,08$ & 0,95 & Tidak Fit \\
GFI & $\geq 0,9$ & 0,81 & Tidak Fit \\
Chi-square & diharapkan kecil & 312,595 & Tidak Fit \\
AGFI & $\geq 0,9$ & 0,790 & Tidak Fit \\
TLI & $\geq 0,95$ & 0,725 & Tidak Fit \\
CFI & $\geq 0,95$ & 0,766 & Tidak Fit \\
Probabilitas & $\geq 0,05$ & 0,00 & Tidak Fit \\
\hline
\end{tabular}

Pada uji linearitas, data yang merupakan outlier atau data ekstrim harus dieliminasi. Cara menentukan data outlier adalah dengan membandingkan mahalanobis distance dengan perhitungan nilai chi-square.

Nilai mahalanobis distance dapat dilihat pada output AMOS dan nilai chi-square dapat dihitung dengan menggunakan microsoft excel. Rumusyang digunakan pada microsoft excel adalah $=$ CHIINV (probability, deg_freedom). Degree of freedom (df) yang dimaksud dalam penelitian ini adalah jumlah indikator yaitu berjumlah 33 dan probability yang digunakan adalah 0,05 maka didapatkan nilai chi-square sebesar 47,40.Selain itu, jika semua nilai mahalanobis distance sudah berada di bawah nilai chi-square, namun nilai p1 dan p2 secara bersama - sama menunjukkan angka 0,000 maka data tersebut dieliminasi.

Pada hasil pengujian terdapat 3 nilai mahalanobis distance yang berada di atas 47,40. Dengan demikian data tersebut harus dieliminasi dan kembali melakukan pengolahan data untuk normalitas dan mahalanobis distance.

Setelah dilakukan eliminasi pada nilai outliers, didapati bahwa nilai skewness sudah berada di $\pm 1,96$ dan nilai kurtosis sudah berada di bawah 10 karena bernilai 9,783. Dengan demikian dapat dikatakan bahwa data sudah normal, dan sudah tidak terdapat nilai mahalanobis distance yang berada di atas 47,40. Dengan demikian tidak ada data yang perlu dieliminasi dan sudah sesuai dengan kriteria. Jumlah sampel menjadi 190 .

Terakhir evaluasi dilakukan pengujian kesesuaian model dengan kriteria goodness of fit. Hasil dari model penelitian akan bandingkan dengan batasan statistik yang telah ditentukan.

Dari hasil tabel 3, model full structural belum fit karena semua kriteria belum terpenuhi. Oleh karena itu, diperlukan modifikasi model agar model tersebut bisa fit. Dikarenakan model diatas belum fit, maka perlukan modifikasi model untuk memperbesar atau memperkecil nilai kriteria dalam goodness of fit untuk membuat model menjadi semakin fit. Modifikasi model dapat dilakukan apabila hasil estimasi model mempunyai residual yang besar. Melalui tabel Standardized Residual Covariens dapat dicermati apakah perlu dilakukan modifikasi pada model. Nilai residual yang lebih besar dari $\pm 1,96$ menunjukkan bahwa model perlu dilakukan modifikasi, dan model pada penelitian ini belum dapat diterima secara bagus, oleh karena itu perlu dilakukan modifikasi terhadap model.

Modifikasi dapat dilakukan dengan menghubungkan error, indikator, ataupun konstruk. Untuk melihat error, indikator, ataupun konstruk yang harus dihubungkan dalam modifikasi model, dapat dilihat pada bagian modification indices. Model akhir dari modifikasi model dalam penelitian ini dapat dilihat pada gambar 8 . 
Tabel 4. Hasil Uji Reliabilitas dan Variance Extract

\begin{tabular}{c|c|c|c|c|c|c}
\hline & std loading & std loading $^{2}$ & $\boldsymbol{E} j$ & $\begin{array}{c}\text { Construct } \\
\text { Reliability }\end{array}$ & $\begin{array}{c}\text { Variance } \\
\text { Extracted }\end{array}$ & $\begin{array}{c}\text { Discriminant } \\
\text { Validity }\end{array}$ \\
\hline \multicolumn{7}{c}{ MOTIVASI [MOT] } \\
\hline X1 & 0.59 & 0.3481 & 0.35 & & \\
X2 & 0.73 & 0.5329 & 0.53 & \multirow{2}{*}{0.74} & 0.50 & 0.71 \\
X4 & 0.34 & 0.1156 & 0.11 & & & \\
TOTAL & 1.66 & 0.9966 & 0.99 & & & \\
\hline
\end{tabular}

\begin{tabular}{c|l|l|l|l|l|l}
\hline X12 & 0.29 & 0.0841 & 0.08 & & & \\
X17 & 0.55 & 0.3025 & 0.30 & & & \\
X18 & 0.72 & 0.5184 & 0.52 & 0.78 & 0.50 & 0.71 \\
X19 & 0.74 & 0.5476 & 0.55 & & & \\
\hline TOTAL & 2.30 & 1.4526 & 1.45 & & & \\
\hline
\end{tabular}

SOFTSKILL [SOFT]

\begin{tabular}{c|l|l|l|l|l|l}
\hline $\mathbf{X 2 0}$ & 0.43 & 0.1849 & 0.19 & & & \\
$\mathbf{X 2 2}$ & 0.73 & 0.5329 & 0.53 & & & \\
$\mathbf{X 2 3}$ & 0.77 & 0.5929 & 0.59 & \multirow{2}{*}{0.82} & 0.50 & 0.71 \\
$\mathbf{X 2 6}$ & 0.41 & 0.1681 & 0.17 & & & \\
$\mathbf{X 2 7}$ & 0.57 & 0.3249 & 0.32 & & & \\
\hline TOTAL & 2.91 & 1.8037 & 1.80 & & & \\
\hline
\end{tabular}

KINERJA [KNJ]

\begin{tabular}{c|c|c|c|c|c|c}
\hline X29 & 0.50 & 0.25 & 0.31 & & & \\
X30 & 0.17 & 0.0289 & 0.03 & & & \\
X31 & 0.76 & 0.5776 & 0.58 & \multirow{2}{*}{0.80} & 0.50 & \\
X32 & 0.66 & 0.4356 & 0.44 & & & \\
X33 & 0.90 & 0.81 & 0.81 & & & \\
\hline TOTAL & 2.99 & 2.1021 & 2.17 & & & \\
\hline
\end{tabular}


Tabel 5. Regression Weight

\begin{tabular}{|c|c|c|c|c|c|c|c|}
\hline & & & Estimate & S.E. & C.R. & $\mathrm{P}$ & Label \\
\hline KNJ & $<---$ & MOT & 0.712 & 0.283 & 2.514 & 0.012 & par_13 \\
\hline KNJ & $<---$ & SOFT & 0.484 & 0.478 & 1.012 & 0.311 & par_15 \\
\hline KNJ & $<---$ & ORG & -0.18 & 0.297 & -0.606 & 0.545 & par_16 \\
\hline $\mathrm{X} 1$ & $<---$ & MOT & 1 & & & & \\
\hline $\mathrm{X} 4$ & $<---$ & MOT & 0.543 & 0.135 & 4.035 & $* * *$ & par_1 \\
\hline X19 & $<---$ & ORG & 1 & & & & \\
\hline $\mathrm{X} 18$ & $<---$ & ORG & 0.974 & 0.125 & 7.772 & $* * *$ & par_2 \\
\hline $\mathrm{X} 17$ & $<---$ & ORG & 0.851 & 0.135 & 6.299 & $* * *$ & par_3 \\
\hline $\mathrm{X} 12$ & $<---$ & ORG & 0.392 & 0.112 & 3.506 & $* * *$ & par_4 \\
\hline $\mathrm{X} 20$ & $<---$ & SOFT & 1 & & & & \\
\hline $\mathrm{X} 22$ & $<---$ & SOFT & 1.658 & 0.31 & 5.347 & $* * *$ & par_5 \\
\hline $\mathrm{X} 23$ & $<---$ & SOFT & 1.982 & 0.382 & 5.19 & $* * *$ & par_6 \\
\hline $\mathrm{X} 26$ & $<---$ & SOFT & 0.958 & 0.239 & 4.017 & $* * *$ & par_7 \\
\hline $\mathrm{X} 27$ & $<---$ & SOFT & 1.245 & 0.264 & 4.721 & $* * *$ & par_8 \\
\hline X33 & $<---$ & KNJ & 1 & & & & \\
\hline $\mathrm{X} 32$ & $<---$ & KNJ & 0.565 & 0.062 & 9.12 & $* * *$ & par_9 \\
\hline X31 & $<---$ & $\begin{array}{l}\mathrm{KN} \\
\mathrm{J}\end{array}$ & 0.764 & 0.071 & 10.739 & $* * *$ & par_10 \\
\hline $\mathrm{X} 30$ & $<---$ & KNJ & 0.119 & 0.049 & 2.421 & 0.015 & par_11 \\
\hline $\mathrm{X} 29$ & $<---$ & KNJ & 0.383 & 0.058 & 6.644 & $* * *$ & par_12 \\
\hline $\mathrm{X} 2$ & $<---$ & MOT & 0.974 & 0.204 & 4.783 & $* * *$ & par 14 \\
\hline
\end{tabular}


Tabel 6. Hasil Pengujian Hipotesis

\begin{tabular}{c|c|c}
\hline \multicolumn{2}{c|}{ Hipotesis } & Keterangan \\
\hline H1 & Motivasi memiliki pengaruh terhadap Kinerja Mahasiswa & Diterima \\
H2 & Organisasi memiliki pengaruh terhadap Kinerja Mahasiswa & Ditolak \\
H3 & Softskill memiliki pengaruh terhadap Kinerja Mahasiswa & Ditolak \\
\hline
\end{tabular}

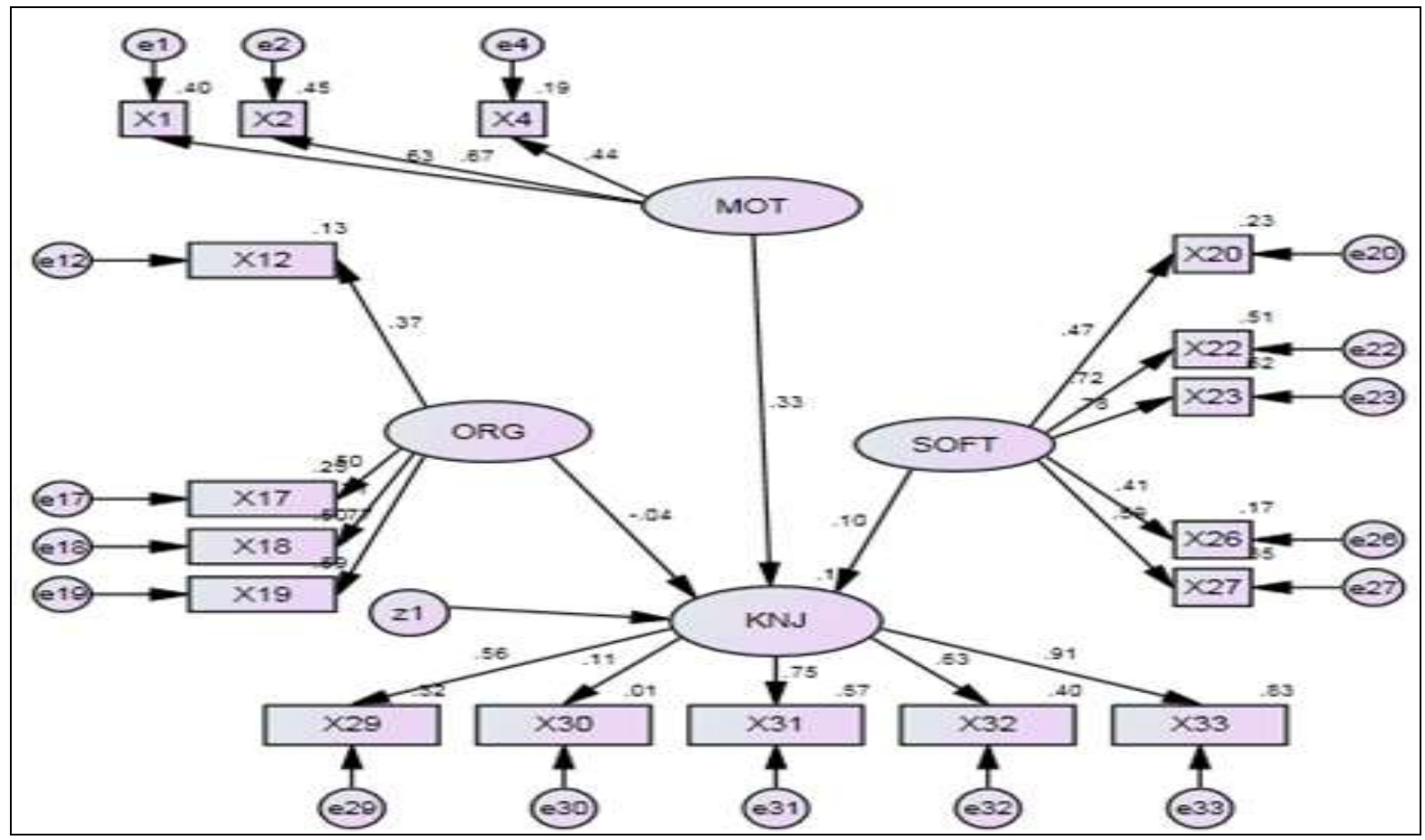

Gambar 8. Model Structural Equation Modifikasi.

Model di atas dinyatakan telah fit karena kriteria goodness of fit telah terpenuhi. Hal ini dapat dilihat dari nilai cmindf sebesar 1,193 yang telah memenuhi kriteria fit yaitu $<2$ berdasarkan Byrne, nilai RMSEA sebesar 0,32 yang telah memenuhi kriteria fit yaitu $<0,08$ dan nilai probabilitas $>0,05$ serta GFI, AGFI, TLI dan CFI sudah memenuhi kriteria.

Tabel 4 di atas menyajikan hasil perhitungan realibilitas dan perhitungan variance extract. Tahapan selanjutnya adalah melakukan uji reliabilitas dan uji validitas. Batasan nilai yang dapat diterima untuk menilai suatu tingkat reliabilitas adalah 0,70 ,untuk nilai AVE (Average Variance Extracted) minimal 0,5 dan nilai $\mathrm{CR}$ (Construct Reliability) 0,7.
Berdasarkan hasil perhitungan di tabel 4, dapat dikatakan bahwa indikator indikator itu telah mewakili secara baik variabel bentukan yang dikembangkan.

Berdasarkan tabel 5 di atas dan dasar pengambilan keputusan, maka dapat diketahui hipotesis yang diterima atau ditolak. Hasil pengujian hipotesis dapat dilihat pada tabel 6 diatas.

\subsection{Implikasi Manajerial}

Berdasarkan pengolahan data dengan software AMOS didapatkan hasil bahwa Motivasi memiliki pengaruh terhadap Kinerja Mahasiswa, sedangkan Organisasi dan Soft skill tidak memiliki pengaruh terhadap Kinerja Mahasiswa. 
Motivasi pada masing - masing individu mahasiswa diperlukan agar dapat memaksimalkan kinerjanya, baik berasal dari dalam diri sendiri maupun melalui orang lain. Seperti diketahui menurut Sardiman, motif diartikan sebagai daya upaya yang mendorong seseorang untuk melakukan sesuatu. Motivasi pada penelitian ini dipengaruhi oleh indikator seperti pentingnya seorang mahasiswa menjadi bagian dalam komunitas kampus, menerima permintaan tolong teman yang mengalami kesulitan, dan berkeinginan untuk mendapatkan hasil yang terbaik dalam mengerjakan suatu tugas.

Dalam kegiatan perkuliahan seorang mahasiswa dapat menjadi bagian komunitas kampus dengan cara mengikuti kegiatankegiatan yang diadakan oleh fakultas maupun universitas, atau lingkup yang lebih kecil yaitu organisasi pada masing - masing program studi. Dalam penelitian ini, mahasiswa diharapkan lebih banyak teribat aktif dalam acara yang satu teknik. Dimana, melalui acara - acara ini, mahasiswa dapat lebih mengenal satu sama lain, bukan hanya dengan sesama mahasiswa, namun juga dengan dosen, karyawan sekretariat dan alumni. Dengan terlibat secara langsung dan melakukan komunikasi secara aktif, bisa menumbuhkan rasa saling memiliki, dan setiap individu memiliki peran yang penting untuk menjaga keutuhan komunitas teknik.

Pada dasarnya, Fakultas Teknik sudah memulai kegiatan - kegiatan dalam komunitas teknik dengan baik, seperti akan diadakannya Reuni Akbar, Fun Run, dan FT Games yang selalu diadakan setiap tahunnya, serta pada tahun - tahun sebelumnya pernah diadakan acara outdoor setiap awal semester ganjil. Keterlibatan mahasiswa secara langsung dalam kegiatankegiatan ini dapat menimbulkan rasa empati satu sama lain yang tentunya dapat mendorong orang lain maupun diri sendiri untuk memberikan sesuatu lebih kepada komunitas karena adanya rasa memiliki.
Melalui komunitas yang lebih kecil, seperti melalu prodi diharapkan mahasiswa akan lebih mudah untuk membangun kebersamaan satu sama lain. Menjadi bagian dari komunitas kampus, juga menuntut mahasiswa dalam memaksimalkan kinerja, karena adanya tanggung jawab lebih dibandingkan dengan lainnya, serta mahasiswa dapat belajar dari senior maupun juniornya karena menjadi keberhasilan bersama.

Indikator kedua yang mendukung motivasi adalah menerima permintaan tolong teman yang mengalami kesulitan yang memiliki pengaruh paling besar. Hal ini dilakukan dengan adanya kegiatan tentoring yang sudah dilaksanakan di FT Unika Atmajaya maupun kegiatan belajar bersama dengan kelompok untuk saling membantu dalam akademik dan non akademik. Adapula kegiatan advisor yang sudah dilakukan oleh Teknik Industri yang lebih memfokuskan pada mahasiswa baru. Kegiatan yang ada pada indikator pertama sebelumnya dapat menjadi dasar yang kuat dalam menjalin kebersamaan dan rasa empati yang sudah terbangun sehingga dapat dengan mudah diterapkan dalam kegiatan perkuliahan. Dengan kegiatan seperti ini secara tidak langsung dapat membangun dorongan bagi individu lainnya untuk dapat lebih baik dalam menyelesaikan tugas maupun ujian serta mengurangi rasa individualisme.

Perlu direfleksi kembali bahwa kegiatan yang sudah ada sebaiknya lebih ditingkatkan terutama pada kegiatan advisor yang sebaiknya juga dilakukan oleh prodi lain dan dilaksanakan secara maksimal. Kegiatan advisor ini akan lebih bermanfaat lagi jika dilakukan hingga mahasiswa tersebut menyelesaikan kuliahnya di Fakultas Teknik. Menurut saya, hal seperti ini dapat menjadi dasar tumbuhnya rasa empati dengan sesama dan merasa memiliki keluarga baru, sehingga nantinya dapat membuat mahasiswa secara tidak langsung menjadi bagian dalam komunitas. Dengan rasa kepedulian yang ada ini diharapkan dapat menumbuhkan motivasi bagi setiap individu 
untuk lebih memaksimalkan kinerjanya karena mendapat perhatian dari orang lain.

Indikator terakhir adalah berkeinginan untuk mendapatkan hasil yang terbaik. Tidak hanya membantu dan memberi motivasi pada orang lain, namun juga diperlukan kepedulian terhadap diri sendiri. Membangun motivasi diri sendiri dengan memilki keinginan serta optimisme untuk mendapat hasil yang terbaik dalam segala hal. Tentunya, hal ini bukan untuk kepentingan diri sendiri, namun dapat juga berdampak positif kepada orang lain. Dapat diketahui secara jelas apabila terdapat keinginan, maka secara tidak langsung dari individu tersebut terdapat suatu dorongan untuk mencapai hasil yang terbaik. Dari keinginan inilah bisa menjadi dasar untuk tidak malu meminta bantuan dan belajar dari teman yang lebih mampu. Misalnya apabila menjadi seorang pemimpin dalam organisasi, dengan berusaha mendapat hasil yang terbaik, diharapkan dapat membawa anggotanya juga terdorong untuk memaksimalkan tugasnya.

\section{DAFTAR PUSTAKA}

Anggraeni, T. Teori Organisasi. Bekasi: Gunadarma University, 2012.

Bulan, E. Analisis Pengaruh Kecerdasan Intelektual dan Kecerdasan Emosional terhadap IPK Mahasiswa Akuntansi Pada Fakultas Ekonomi Universitas Hasanuddin (Studi Empiris). Skripsi Fakultas Ekonomi Jurusan Akuntansi Universita Hasanuddin. Makasar, 2012.

Byrne, B. M. A primer of LISREL: Basic applications and programming for confirmatory factor analytic models. Springer Science \& Business Media, 2012.

Carmines, E.G. \& McIver, J.P. Analyzing models with unobserved variables. In Bohrnstedt, G.W. \& Borgatta, E.F. [Eds.] Social measurement: Current issues. Beverly Hills: Sage, 1981.

Dale, E. Planning and Developing the Company Organization Structure.New York: AMA, 1959.
Danko, K., Duke, J.C., \& Franz, D.P. Predicting Student Performance in Accounting Classes. Journal of Education for Business, 270-274, 1992.

Djaali. Psikologi Pendidikan. Jakarta: Bumi Aksara, 2008.

Elfindri dkk. Soft Skills Untuk Pendidik. Baduose Media, 2011.

Febriana, B. dkk. Hubungan Antara Keaktifan Organisasi dengan Prestasi Belajar Mahasiswa Fakultas Ilmu Keperawatan Universitas Indonesia.Prosiding Konferensi Nasional PPNI Jawa Tengah 2013. (pp.154-157). Semarang : Universitas Islam Sultan Agung, 2013.

Ferdinand, A. Structural Equation Modeling. BP Undip, 2005.

Foster, Bill, \& Karen R. Pembinaan Untuk Meningkatkan Kinerja Karyawan. Penerjemah : Ramlan, PPM. Jakarta, 2001.

Ghozali, Imam. Model Persamaan Struktural. Semarang: Badan Penerbit Universitas Diponegoro, 2004.

Gintings, A. Esensi Praktis Belajar dan Pembelajaran. Bandung: Humaniora, 2008.

Goleman, D. Kecerdasan Emosional. Jakarta: PT. Gramedia Pustaka Utama, 2007.

Guilford, J.P., Fruchter, Benjamin. Fundamental statistics in psychology and education. Tokyo: McGraw-Hill, Inc, 1978.

Hamdu \& Agustina. Pengaruh motivasi belajar siswa terhadap prestasi belajar IPA di sekolah dasar. Jurnal Penelitian Pendidikan, Vol. 12 (1), 2011.

Herzberg, F. .Dasar - Dasar Manajemen. Diterjemahkan oleh Malayu S.P Hasibuan. Edisi Kedua. Jakarta : Bumi Aksara, 2003.

Karyantoro. Manajemen Sumber Daya Manusia Organisasi Pelayanan Publik. Edisi Pertama. Bandung : Ganesa, 2004.

Kast, F.E. \& Rosenzweig, J.E. Organisasi Dan Manajemen. Terjemahan Hasyim Ali. Jakarta: Bumi aksara, 2005. 
Kline, R. B .Manajemen Pemasaran. Jakarta : PT. Indeks, 2005.

Kuhnel, J., Sonnentag. S., Bledow, R. Resources and time pressure as daylevel antecedents of work engagement. Journal of Occupational and Organizational Psychology,85 : 181198, 2011.

Maier, H.W. Three Theories of Child Development. New York: Harper \& Row Publisher, 1965.

Mangkunegara, A. Manajemen Sumber Daya Manusia. Bandung: PT. Remaja Rosda karya, 2007.

Maslow, A. Motivasi dan Kepribadian, Seri Manajemen. Jakarta: PT. Pustaka Binaman Pressindo, 1984.

Mooney,D.J. Konsep Pengembangan Organisasi Publik. Bandung: Sinar Baru Algesindo, 1996.

Mulyono, I. Dari Karya Tulis Ilmiah Sampai Dengan Soft Skills. Bandung: Yrama Widya, 2011.

Munandar. Psikologi Industri dan Organisasi. Depok : Penerbit Universitas Indonesia (UI Press), 2001.

Muttaqiyathun, A. Hubungan Emotional Quotient, Intelectual Quotient Dan Spiritual Quotient Dengan Entrepreneur's Performance Sebuah Studi Kasus Wirausaha. INTERNATIONAL RESEARCH JOURNAL OF BUSINESS STUDIES, 2(3), 2012.

Nilawati, L. \& Bimo, I. Pengaruh motivasi pada kinerja belajar. Jurnal Manajemen Bisnis, Vol.3 (3) : 287-303, 2010.

Nilawati, L. \& Bimo, I.D. Pengaruh Motivasi Belajar Pada Kinerja Belajar. Jurnal Manajemen Bisnis, Vol. 1 (1) : 287-303, 2010.

Oktavita, F. Pengaruh Kepribadian Proaktif Terhadap Kinerja Belajar Pada Mahasiswa Akuntansi Dengan Motivasi Belajar Sebagai Variabel Intervening. Jurnal Ilmiah. Jurusan Akuntansi, Fakultas Ekonomi dan Bisnis, Universitas Brawijaya. Malang, 2014.
Porter, L.W. \& Lawler, E.E. Managerial attitudes and performance. Homewood, IL: Dorsey Press, 1976.

Pratiwi. Upaya Meningkatkan Aktivitas Dan Hasil Belajar Akuntansi Siswa Melalui Model Pembelajaran Problem Based Instruction (PBI)Pada Siswa Kelas XI AK SMK Putra Anda Binjai Tahun Ajaran2012/2013. Skripsi. Universitas Negeri Medan, 2012.

Prawira, P. Psikologi Pendidikan dalam Perspektif Baru. Yogyakarta: Arruz Media, 2012.

Purwanto. Instrumen Penelitian Sosial dan pendidikan. Yogyakarta : Pustaka Purwanto, M. (2006). 2007.

Riani, A.L. Budaya Organisasi. Yogjakarta: Graha Ilmu, 2011.

Sailah, I. (2007). Pengembangan Soft Skills di perguruan Tinggi. Jakarta : Direktorat Jendral Perguruan Tinggi.

Sandiyah, H. Pengaruh Kecerdasan Intelektual (IQ), Kecerdasan Emosional (EQ) dan Kecerdasan Spiritual (SQ) Terhadap Kinerja Karyawan. Skripsi Universitas Islam Negeri (UIN) Maulana Malik Ibrahim. Malang, 2011.

Sandjojo, N. Metode Analisis Jalur (Path Analysis) dan Aplikasinya, Cetakan Pertama. Jakarta, Penerbit Pustaka Sinar Harapan, 2011.

Sardiman. Interaksi dan Motivasi Belajar Mengajar. Jakarta : Raja Grafindo Persada, 2004.

Sardiman. Interaksi dan Motivasi Belajar Mengajar. Jakarta : PT Raja Grafindo Persada, 2007.

Simanjuntak, P. J. Manajemen dan Evaluasi Kinerja. Jakarta: FE UI, 2005.

Slameto. Belajar dan Faktor - faktor yang mempengaruhi. Jakarta : Rineka Cipta, 2010.

Soemanto, W. .Psikologi Pendidikan. Rineka Cipta, 2003.

Sugiartiningsih \& Suryono, W. Pengaruh Motivasi Terhadap Kinerja Mahasiswa (Studi Kasus Pembelajaran Ekonomi Publik di Fakultas Ekonomi Universitas Widyatama). Jurnal Techno Sosio Economika, Vol.4 (1) : 72-82, 2011. 
Sutrisno, H. Metodologi Research untuk Penulisan Paper, Skripsi, Thesis dan Disertasi, Jilid Tiga.Yogyakarta : Penerbit Andi, 2001.

Trisnawati, N. Pengaruh Kecerdasan Intelektual, Kecerdasan Emosional, Kecerdassan Spiritual Terhadap Kinerja Mahasiswa (Studi Kasus Pada Fakultas Ekonomi Universitas Udayana). 2012. Skripsi. Universitas Udayana, 2012.

Vroom,VH. Work and motivation. New York: Wiley, 1964.

Walpole, Ronald E., Raymond H Myers. Ilmu Peluang Dan Statistika untuk Insinyur dan Ilmuawan. Bandung: ITB, 1995.

Weber, M. .Economy and Society: An Outline of Interpretive Sociology. 2 vol. Barkeley and Los Angeles: University of California Press, 1978.

Widayanti, R. Pengaruh Hard Skill dan Soft Skill Terhadap Kinerja Karyawan. Jurnal Dinamika Dotcom, Vol 3 (1), 2012.

Widodo, B. Pengembangan Soft Skills di Perguruan Tinggi. Jakarta : Departement Pendidikan Nasional, 2008.

Zulganef. Pemodelan Persamaan Struktur dan Aplikasinya menggunakan AMOS 5. Bandung : Pustaka, 2006. 